\title{
Oral Health Consequences of Use of Smokeless Tobacco in North India: A Cross-Sectional Survey
}

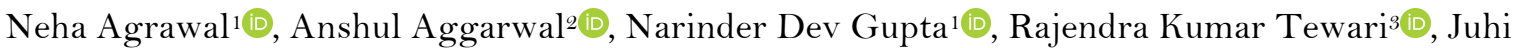 \\ Gupta $^{2}$, Amit Kumar Garg ${ }^{4}$ (อ)
}

\begin{abstract}
${ }^{1}$ Department of Periodontics and Community Dentistry, Dr. Z. A. Dental College, Aligarh Muslim University, Aligarh, India. ${ }^{2}$ Department of Oral Pathology/Oral Medicine \& Radiology, Dr. Z. A. Dental College, Aligarh Muslim University, Aligarh, India. ${ }^{3}$ Department of Conservative Dentistry and Endodontics, Dr. Z. A. Dental College, Aligarh Muslim University, Aligarh, India. ${ }^{4}$ Department of Conservative Dentistry and Endodontics, Maharana Pratap College of Dentistry \& Research Center, Madhya Pradesh Medical Science University, Jabalpur, Gwalior, India.
\end{abstract}

Correspondence: Anshul Aggarwal, Department of Oral Pathology/Oral Medicine \& Radiology, Dr. Z. A. Dental College, Aligarh Muslim University, Aligarh, UP, India. E-mail: draggarwal.xray@gmail.com

Academic Editor: Alessandro Leite Cavalcanti

Received: 02 June 2020 / Review: 16 August 2020 / Accepted: 19 September 2020

How to cite: Agrawal N, Aggarwal A, Gupta ND, Tewari RK, Gupta J, Garg AK. Oral health consequences of use of smokeless tobacco in North India - a cross-sectional survey. Pesqui Bras Odontopediatria Clín Integr. 2021; $21:$ e0114. https://doi.org/10.1590/pboci.2021.025

\begin{abstract}
Objective: To evaluate the effects of commonly used smokeless tobacco forms on oral health at habitual placement sites of smokeless tobacco compared to non-placement sites among the North Indian population. Material and Methods: This cross-sectional study was conducted among 542 individuals using smokeless tobacco recruited from the outpatient wing of the Dental College. Subjects completed a questionnaire and received an oral examination. Periodontal pocket depth, gingival index, plaque index, gingival recession, and oral mucosal changes were assessed. Kendal's Tau test, paired t-test, and chi-square test were carried out to compare different variables among placement and non-placement sites. Results: Most of the subjects were male, reporting an average of 11.26 years of SLT use. Clinical inflammation of gingiva was significantly greater $(\mathrm{p}=0.01)$ at placement-sites $(1.64 \pm 0.53)$ of SLT in comparison to non-placement-sites $(1.40 \pm 0.41)$. The difference in the GR and PPD at placement and non-placement-sites was also statistically significant with $\mathrm{p}=0.002$ and $\mathrm{p}=0.001$, respectively. Clinically, the majority of subjects had mucosal changes at the placement sites, and a statistically significant association $(\mathrm{p}=0.034)$ was observed between the duration of the use of smokeless tobacco and the mucosal changes. Conclusion: Smokeless tobacco use predisposes to increased risk of periodontal diseases and oral mucosal changes at the placement sites in an individual due to the local irritant effect.
\end{abstract}

Keywords: Periodontitis; Tobacco, Smokeless; Mouth Mucosa; Oral Health. 


\section{Introduction}

The global tobacco epidemic has resulted in various adverse health effects and is the leading cause of death worldwide. It is considered the most significant public health threat globally, accounting for more than 7 million deaths annually [1]. Over the ages, tobacco use has increased in India. Of the estimated $28.6 \%$ tobacco use in India, $21.4 \%$ is used in the form of smokeless tobacco (SLT) products such as pan (a blend of lime, bits of areca nut, and spices enclosed in betel leaf), gutka/pan masala (blend of pulverized lime and areca nut) and mishri (used as toothpaste for scouring gums) [2].

Tobacco use is linked with impaired immune system and wound healing, which may play an important role in periodontal tissue destruction [3]. SLT use has been reported to be associated with numerous oral manifestations localized at the SLT placement site in the oral cavity, which can be considered the Placementsite. These manifestations include mucosal lesions as leukoplakia, oral cancer, gingival-periodontal effects, gingival recession, gingival inflammation, gingival blood flow changes, and interproximal periodontal attachment loss and dental caries [4-6].

The localized nature of SLT induced alterations implies that chemical or mechanical irritation from the tobacco quid is responsible for clinical alterations, although bacterial or host factors may influence these lesions' development [7].

The deleterious effects of smoking on oral health have been extensively studied, reported, and gained scientific evidence compared to SLT [8,9]. Limited studies have been carried out in the North Indian population regarding the effect of smokeless tobacco products on the periodontium and oral health [10,11]. Therefore, this study was carried out to evaluate the effects of commonly used smokeless tobacco forms on the periodontium and oral health at habitual placement-sites of SLT and compare it to non-placement-sites SLT in the same individuals among North Indian population. The study results will help provide recommendations for future planning of tobacco cessation activities, preventive, and treatment programs.

\section{Material and Methods}

Study Design and Sample

This cross-sectional study was conducted among the individuals in the age range of 18-60 years, using smokeless tobacco, from the outpatient wing of the Dental College, Aligarh Muslim University.

\section{Ethical Consideration}

Ethical clearance was obtained from the Institutional Ethical Review Board (Protocol No. 359/FM dated $27 / 5 / 17)$. Informed consent was obtained from the patients before the start of the study. Participation in the study was voluntary and confidentiality of data was maintained.

\section{Inclusion and Exclusion Criteria}

Patients aged 18-60 years, using smokeless tobacco, and having at least 10 teeth were included in the study. Patients with tobacco smoking habits, complete edentulous status, systemic diseases, under medication, and patients who underwent surgery in the past 6 months, pregnant and lactating females were excluded from the study. 
The sample size was calculated using the following formula: $\mathrm{Z}^{2}=$ Standard score corresponding to a given confidence level; $\mathrm{P}=$ Prevalence of disease; $\mathrm{q}=(1-\mathrm{p})$ or percentage of failure which is $100-1=99 \%$; and $\mathrm{e}=$ Precision limit or proportion of sampling error which is usually $5 \%$ confidence limit; where $\mathrm{Z}=1.96, \mathrm{P}$ $=16 \%=0.16[12]$, Absolute level of precision (e) which specifies the width of the confidence interval was kept as $5 \%$. According to the above-given formula, the final sample size obtained was 206. The sample size was increased to 542 as larger sample sizes give more reliable results with greater precision and power.

\section{Data Collection}

The information was recorded on a self-prepared questionnaire, consisting of demographic details, SLT use status, and oral hygiene. A complete intraoral examination was carried out on a dental chair in dental college by a single dentist using diagnostics (mouth mirror, explorer, UNC 15 probe, cotton pliers and Naber's probe) instruments including an assessment of gingival index (GI; Loe and Silness), plaque index (PI; Silness and Loe), periodontal pocket depth (PPD), using University of North Carolina 15 probe (UNC 15 probes, HuFriedy Mfg. Co., Inc, USA), gingival recession (GR; P. D. Miller classification). The dentist was fully equipped with personal protective equipment. Clinically, oral mucosal changes in the form of typically wrinkled appearance were also recorded at the placement sites of smokeless tobacco [13].

\section{Standardization and Calibration}

Standardization and calibration of the dentist were performed regarding the diagnostic criteria through comprehensive written instructions, practice, and through discussing clinical cases.

\section{Pilot Study}

A pilot study was conducted to pretest the questionnaire on 75 individuals who were not included in the main study and comprised $15 \%$ of the study sample. The questionnaire's reliability was assessed using testretest, and the questionnaire's internal consistency was ascertained by Chronbachs-Alpha ( $\alpha)$. The mean Kappa value was found to be 0.90 . The overall internal reliability of the questionnaire was 0.72 , according to Cronbach's alpha. Therefore, no changes were required in the questionnaire.

\section{Statistical Analysis}

The collected data were analyzed using Statistical Package for Social Sciences (SPSS) 16.0 (version 16 for Windows, IBM Corp., Armonk, NY, USA) and descriptive and analytical tests, including mean, standard deviation, were calculated. Kendal's Tau test, paired t-test, and Chi-square test were carried out to compare different variables between placement and non-placement sites. The p-value $<0.05$ was considered as statistically significant.

\section{Results}

For the present cross-sectional study, a total of 542 subjects were selected on the basis of the habitual use of different forms of smokeless tobacco (SLT). Most of the participants were male (63.83\%) and brushed their teeth daily (84.13\%). The demographic information is summarized in Table 1. The participants' mean age was 36.23 years, reporting an average of 11.26 years of SLT use. Among the different types of smokeless tobacco products used, betel leaf with tobacco and gutkha $(27.49 \%)$ was the most commonly consumed, followed by tobacco with lime (23.25\%). 
Table 1. Socio-demographic details of the patients.

\begin{tabular}{|c|c|}
\hline Characteristics & $\mathbf{N}(\%)$ \\
\hline \multicolumn{2}{|l|}{ Gender } \\
\hline Male & $346(63.83)$ \\
\hline Female & $196(36.26)$ \\
\hline \multicolumn{2}{|l|}{ Age Distribution (Years) } \\
\hline$\leq 20$ & $48(8.86)$ \\
\hline $21-30$ & $156(28.78)$ \\
\hline $31-40$ & $242(44.65)$ \\
\hline $41-50$ & $78(14.39)$ \\
\hline$>50$ & $18(3.32)$ \\
\hline Mean $\pm \mathrm{SD}$ & $36.23 \pm 8.3$ \\
\hline \multicolumn{2}{|l|}{ Education Level } \\
\hline Profession or Honours & $14(2.62)$ \\
\hline Graduate or Postgraduate & $68(12.54)$ \\
\hline Intermediate or Post High School Diploma & $83(15.31)$ \\
\hline High School Certificate & $61(11.24)$ \\
\hline Middle School Certificate & $183(33.76)$ \\
\hline Primary School Certificate & $115(21.21)$ \\
\hline Literate & $18(3.32)$ \\
\hline \multicolumn{2}{|l|}{ Oral Hygiene } \\
\hline Brush Daily & $456(84.13)$ \\
\hline Brush Weekly & $64(11.82)$ \\
\hline$<$ Once a Week & $15(2.76)$ \\
\hline Never & $7(1.29)$ \\
\hline \multicolumn{2}{|l|}{ Type of Smokeless Tobacco Used } \\
\hline Tobacco with Paan (Betel Leaf) & $104(19.19)$ \\
\hline Tobacco Dentifrices & $52(9.59)$ \\
\hline Tobacco with Betel Nut and Gutkha & $111(20.48)$ \\
\hline Paan (Betel Leaf) with Tobacco and Gutkha & $149(27.49)$ \\
\hline Tobacco with Lime & $126(23.25)$ \\
\hline \multicolumn{2}{|l|}{ Duration of Smokeless Tobacco Use (Years) } \\
\hline$\leq 5$ & $78(14.39)$ \\
\hline $6-10$ & $286(52.77)$ \\
\hline $11-15$ & $95(17.53)$ \\
\hline $16-20$ & $51(9.41)$ \\
\hline$>20$ & $32(5.90)$ \\
\hline
\end{tabular}

The periodontal clinical parameters of the study population are presented in Table 2. Clinical inflammation of gingiva as measured by the gingival index was significantly greater $(p=0.01)$ at the placementsite $(1.64 \pm 0.53)$ of SLT in comparison to non-placement-site $(1.40 \pm 0.41)$. Accumulation of plaque was more at the placement-site of smokeless tobacco $(1.52 \pm 0.39)$ than non-placement-site $(1.50 \pm 0.37)$, but the difference was not statistically significant $(\mathrm{p}=0.51)$. The difference in the pocket probing depth at placement $(2.42 \pm 0.63)$ and non-placement sites $(3.29 \pm 0.95)$ was statistically significant $(\mathrm{p}=0.001)$ with greater pocket probing depth at non-placement site.

Table 2. Comparison of Clinical periodontal parameters between placement and non placement sites of smokeless tobacco.

\begin{tabular}{lc}
\hline \multicolumn{1}{c}{ Periodontal Parameters } & Mean (SD) \\
\hline Gingival Index Sites & $1.64 \pm 0.53$ \\
Placement Site & $1.40 \pm 0.41$ \\
Non-placement Site & $0.24 \pm 0.12$ \\
Mean Difference (95\% CI) $\quad$ p-value & $0.01^{*}$ \\
Plaque Index $\quad 1.52 \pm 0.39$ &
\end{tabular}




\begin{tabular}{cc}
\multicolumn{1}{l}{$\begin{array}{l}\text { Non-placement Site } \\
\text { Mean Difference (95\% CI) } \\
\text { p-value }\end{array}$} & $1.50 \pm 0.37$ \\
Pocket Probing Depth & $0.02 \pm 0.02$ \\
Placement Site & 0.51 \\
Non-placement Site & $2.42 \pm 0.63$ \\
Mean Difference (95\% CI) & $3.29 \pm 0.95$ \\
p-value & $0.87 \pm 0.32$ \\
*Statistically Significant (Paired T Test). & $0.001^{*}$ \\
\hline
\end{tabular}

More than half of the placement sites of SLT users (65.7\%) showed gingival recession compared to non-placement sites of SLT where only $32.3 \%$ of sites showed gingival recession (Table 3). There was a statistically significantly higher gingival recession $(\mathrm{p}=0.002)$ at placement sites of SLT than non-placement sites of SLT among various classes of Miller's classification of gingival recession.

Table 3. Comparison of gingival recession.

\begin{tabular}{lccccccccc}
\hline \multicolumn{1}{c}{ Site } & \multicolumn{2}{c}{ Normal } & \multicolumn{2}{c}{ Class I } & \multicolumn{2}{c}{ Class II } & \multicolumn{2}{c}{ Class III } & \multicolumn{2}{c}{ p-value } \\
& $\mathrm{N}$ & $\%$ & $\mathrm{~N}$ & $\%$ & $\mathrm{~N}$ & $\%$ & $\mathrm{~N}$ & $\%$ \\
\hline Placement Site & 186 & 34.3 & 220 & 40.7 & 107 & 19.7 & 29 & 5.3 & $0.002^{*}$ \\
Non-Placement Site & 367 & 67.7 & 123 & 22.6 & 30 & 5.6 & 22 & 4.1 \\
\hline
\end{tabular}

*Kendall's Tau Test.

Clinically, most subjects had mucosal changes at the placement sites compared to non-placement sites of smokeless tobacco (16.42\%), as shown in Table 4. A statistically significant association $(p=0.034)$ was observed between the duration of smokeless tobacco and the mucosal changes observed (Table 5).

Table 4. Comparison of mucosal changes.

\begin{tabular}{lccccc}
\hline \multirow{2}{*}{ Site (542) } & \multirow{2}{*}{ Normal } & Mucosal Changes & \multicolumn{2}{c}{} \\
& & $\mathrm{D}-1$ & $\mathrm{D}-2$ & $\mathrm{D}-3$ & p-value* \\
& & $\mathrm{N}(\%)$ & $\mathrm{N}(\%)$ & $\mathrm{N}(\%)$ & 0.002 \\
\hline Placement & $77(14.21)$ & $224(41.35)$ & $158(29.21)$ & $83(15.23)$ & $0.0)$ \\
\hline Non-placement & $453(83.57)$ & $89(16.42)$ & $0(0.0)$ & $0(0)$ & \\
\hline
\end{tabular}

*Kendall's Tau Test.

Table 5. Association of duration of smokeless tobacco use and mucosal changes.

\begin{tabular}{lcccccc}
\multirow{2}{*}{ Duration of Tobacco Use } & Total & Normal & D-1 & D-2 & D-3 & p-value* \\
& $\mathrm{N}(\%)$ & $\mathrm{N}(\%)$ & $\mathrm{N}(\%)$ & $\mathrm{N}(\%)$ & $\mathrm{N}(\%)$ & 0.034 \\
\hline$\leq 5$ Years & $78(14.39)$ & $14(18.23)$ & $28(35.32)$ & $23(29.45)$ & $13(17.00)$ & \\
6-10 Years & $286(52.77)$ & $50(17.43)$ & $81(28.31)$ & $95(33.22)$ & $60(21.04)$ & \\
1 1-15 Years & $95(17.53)$ & $13(13.21)$ & $26(27.36)$ & $32(34.12)$ & $24(25.26)$ & \\
16-20 Years & $51(9.41)$ & $5(10.34)$ & $11(21.34)$ & $19(36.2)$ & $16(32.21)$ \\
$>20$ Years & $32(5.90)$ & $3(10.53)$ & $9(27.44)$ & $13(39.7)$ & $7(22.33)$ & \\
\hline
\end{tabular}

*Chi-Square Test.

\section{Discussion}

There is a greater prevalence of using smokeless tobacco in India than smoking tobacco, not only among males but also females. The type of tobacco use differs between different ages, gender, and social classes [2]. In the Southeast Asia Region, SLT use among adults is higher than smoking, which is different from other regions of the world [12].

This cross-sectional study was designed to determine the effect of smokeless tobacco on the periodontium and oral mucosa at the placement-sites (SLT-sites) compared to non-placement sites (NSLT- 
sites). The finding of this study revealed that SLT-sites, compared to NSLT-sites, experienced greater gingival inflammation and gingival recession and a higher prevalence of mucosal alterations but lesser periodontal pocket depth. In the present study, consumption of smokeless tobacco was found to be twice amongst males as compared to females. This result was in line with other studies where tobacco consumption was more common among males [14,15]. The higher prevalence of use of SLT among males has been attributed to the fact that the concentration of economic powers in the hands of males and is due to their proneness to stress situations and the assumption that SLT use helps them to carry out their occupational tasks with more concentration $[15]$.

In the present study, the prevalence of tobacco use was lower among the younger youth aged $<20$ years compared to older ones aged 31-40 years and above; this finding was consistent with other study conducted in Rwandan youth aged 15-34 years. It may be because of insufficient income and lesser exposure to tobacco advertising. This finding provides us an opportunity to act and stop the youths from becoming tobacco users. Therefore, various tobacco cessation initiatives like behavioral interventions would be vital to help these young people refrain from using tobacco [16].

In the current study, the majority of patients were having an education level till middle school certificate and were found to have an increased level of periodontitis. Various studies have reported stressors like poor family relations and low school satisfaction, poor grades in school and peer group pressure amongst adolescents and young adults as the reason behind this finding [17]. This was in agreement with the other study and a review where it was revealed that low educational attainment was associated with an increased risk of periodontitis [18,19].

The clinical finding on the gingival index was significantly higher at placement sites $(1.64 \pm 0.53)$ of SLT compared to non-placement sites of SLT $(1.40 \pm 0.41)$. SLT products contain a high concentration of volatile $\mathrm{N}$-nitrosamines, tobacco-specific N-nitrosamines, $\mathrm{N}$-nitrosamino and the $\mathrm{pH}$ ranged from 5.3 to 8.9 [20]. This suggests that smokeless tobacco's irritational properties, either chemical or mechanical, may contribute to the increased inflammation at the site of placement. These results were in line with several studies $[4,21]$ but in contrast with several other studies where no association was found between smokeless tobacco use and gingival inflammation, which might be due to vasoconstriction caused by nicotine [22,23].

Plaque levels were insignificantly higher at placement-site (1.52 \pm 0.39$)$ compared to non-placementsites $(1.50 \pm 0.37)$. These findings were consistent with studies conducted by Montén et al. [22] and Singh et al. [17]. However, Wolfe et al. [21] and Robertson et al. [22] found less frequent plaque and calculus formation at the site of smokeless tobacco use.

Pocket probing depth was found to be lower at placement sites $(2.42 \pm 0.63)$ compared to nonplacement sites $(3.29 \pm 0.95)$ of SLT. It was probably due to an increased degree of gingival recession. A similar result was observed in another study [24].

In the present study, among different types of SLT users, $65.7 \%$ had a gingival recession, which suggests a strong association between SLT use and GR. This finding is in line with other studies carried out by Offenbacher et al. [25] and Anderson et al. [26]. It was reported in different studies that the consumption of tobacco in any form leads to poor periodontal status and severe active disease than adults who had never used tobacco $[27,28]$.

There was a statistically significant association between sites of placement of smokeless tobacco and oral lesions. Mucosal changes were prevalent at the placement-sites in comparison to non-placement-sites. The 
oral tissues of SLT users were exposed to high nicotine and other tobacco byproducts concentration that negatively affected the local cell population. Several authors have reflected similar results [5,29,30].

In the present study, gingival inflammation, gingival recession, and mucosal alterations were found to be higher at the placement-sites of SLT in comparison to non-placement-sites of SLT, which showed that SLT has potential localized action and deleterious effect on oral health. Thus, the oral health of the general population in the region of North India required immediate attention. The present study results can act as a motivation for the users of tobacco to quit the habit of taking smokeless tobacco.

One of our study's limitations was the cross-sectional nature, which prevents us from making any temporal association between oral health effects and smokeless tobacco use. Secondly, there was more heterogeneity in the type of smokeless tobacco products used and the study patients' oral hygiene practices, which could have affected our results. Therefore, longitudinal studies with a larger sample size need to be carried out to ascertain these results.

\section{Conclusion}

Smokeless tobacco use predisposes to an increased risk of periodontal diseases and oral mucosal changes in an individual. In addition, there is convincing proof to support the significant benefits of tobacco use cessation concerning various oral health outcomes. Therefore, all healthcare providers should assess the patients' tobacco usage habits and actively employ tobacco prevention, cessation, and treatment programs in a variety of populations across all ages.

\section{Authors' Contributions}

\begin{tabular}{|c|c|c|}
\hline NA & (iD) https://orcid.org/0000-0001-6034-9675 & Conceptualization, Methodology, Formal Analysis, Investigation and Writing - Original Draft. \\
\hline AA & (iD) https://orcid.org/0000-0001-8074-164X & Conceptualization and Writing - Review and Editing. \\
\hline NDG & (iD) https://orcid.org/0000-0002-5669-5716 & Conceptualization and Writing - Review and Editing. \\
\hline RKT & https://orcid.org/0000-0002-61 16-5592 & Conceptualization and Writing - Review and Editing. \\
\hline JG & https://orcid.org/0000-0002-1370-4299 & Conceptualization and Writing - Review and Editing. \\
\hline $\mathrm{AKG}$ & (D) https://orcid.org/0000-0003-1561-7866 & Conceptualization and Writing - Review and Editing. \\
\hline
\end{tabular}

\section{Financial Support}

None.

\section{Conflict of Interest}

The authors declare no conflicts of interest.

\section{Data Availability}

The data used to support the findings of this study can be made available upon request to the corresponding author.

\section{References}

[1] Tobacco. World Health Organization. Available from: https://www.who.int/news-room/fact-sheets/detail/tobacco. [Accessed on August 10, 2020].

[2] Global adult tobacco survey Fact Sheet India 2016-17. World Health Organization. Available from: https://www.who.int/tobacco/surveillance/survey/gats/GATS_India_2016-17_FactSheet.pdf. [Accessed on December 25, 2019].

[3] Kamath KP, Mishra S, Anand PS. Smokeless tobacco use as a risk factor for periodontal disease. Front Public Health 2014; 2:195. https://doi.org/10.3389/fpubh.2014.00195

[4] Chu YH, Tatakis DN, Wee AG. Smokeless tobacco use and periodontal health in a rural male population. J Periodontol 2010; 81(6):848-54. https://doi.org/ 10.1902/jop.2010.090310

[5] Walsh PM, Epstein JB. The oral effects of smokeless tobacco. J Can Dent Assoc 2000; 66(1):22-5. 
[6] Mecklenburg RE, Greenspan D, Kleinman DV, Manley MW, Niessen LC, Roberteson PB, et al. Tobacco effects in the mouth. A National Cancer Institute and National Institute of Dental Research Guide for Health Professionals Washington: US Department of Health and Human Services. Public Health Service; 1992; 28p.

[7] Johnson GK, Poore TK, Payne JB, Organ CC. Effect of smokeless tobacco extract on human gingival keratinocyte levels of prostaglandin E2 and interleukin-1. J Periodontol 1996; 67(2):116-24. https://doi.org/10.1902/jop.1996.67.2.116

[8] Komar K, Glavina A, Boras VV, Verzak Ž, Brailo V. Impact of smoking on oral health: knowledge and attitudes of Croatian dentists and dental students. Acta Stomatol Croat 2018; 52(2):148-55. https://doi.org/10.15644/asc52/2/8

[9] Gautam DK, Jindal V, Gupta SC, Tuli A, Kotwal B, Thakur R. Effect of cigarette smoking on the periodontal health status: a comparative, cross sectional study. J Indian Soc Periodontol 2011; 15(4):383-7. https://doi.org/10.4103/0972-124X.92575

[10] Singh GP, Rizvi I, Gupta V, Bains VK. Influence of smokeless tobacco on periodontal health status in local population of north India: A cross-sectional study. Dent Res J 2011; 8(4):211-20. https://doi.org/10.4103/1735-3327.86045

[11] Kumar S, Mehrotra D, Mishra S, Goel MM, Kumar S, Mathur P, et al. Epidemiology of substance abuse in the population of Lucknow. J Oral Biol Craniofac Res 2015; 5(3):128-33. https://doi.org/10.1016/j.jobcr.2015.08.010

[12] IARC Working Group on the Evaluation of Carcinogenic Risks to Humans. Betel-quid and areca-nut chewing and some areca-nut derived nitrosamines. IARC Monogr Eval Carcinog Risks Hum 2004; 85:1-334.

[13] Axéll T, Andersson G, Larsson A. Oral mucosal findings associated with chewing tobacco in Sweden - a clinical and histological study. J Dent Assoc S Afr 1992; 47(5):194-6.

[14] Sreeramareddy CT, Pradhan PM, Mir IA, Sin S. Smoking and smokeless tobacco use in nine South and Southeast Asian countries: prevalence estimates and social determinants from demographic and health surveys. Popul Health Metr 2014; 12:22. https://doi.org/10.1186/s12963-014-0022-0

[15] Lakew Y, Haile D. Tobacco use and associated factors among adults in Ethiopia: further analysis of the 2011 Ethiopian Demographic and Health Survey. BMC Public Health 2015;15:487. https://doi.org/10.1186/s12889-015-1820-4

[16] Habiyaremye F, Rwunganira S, Musanabaganwa C, Muhimpundu MA, Omolo J. Tobacco use and associated factors among Rwandan youth aged 15-34 years: Findings from a nationwide survey, 2013. PLoS One 2019; 14(10):e02 12601. https://doi.org/10.1371/journal.pone.0212601

[17] Mukherjee K, Hadaye RS. Gutkha consumption and its determinants among secondary school male students. Indian J Community Med 2006; 31(3):177.

[18] Gomes AP, da Silva EG, Gonçalves SHF, Huhtala MFRL, Martinho FC, Gonçalves SEP, et al. Relationship between patient's education level and knowledge on oral health preventive measures. Int Dent Med J Adv Res 2015; 1:1-7. https://doi.org/10.15713/ins.idmjar.6

[19] Boillot A, El Halabi B, Batty GD, Rangé H, Czernichow S, Bouchard P. Education as a predictor of chronic periodontitis: a systematic review with meta-analysis population-based studies. PLoS One 2011; 6(7):e21508. https://doi.org/10.1371/journal.pone.0021508

[20] IARC Working Group on the Evaluation of Carcinogenic Risks to Humans. Smokeless Tobacco and Some Tobaccospecific N-Nitrosamines. IARC Monogr Eval Carcinog Risks Hum, No. 89.) 1, Description of Smokeless Tobacco Practices. Available from: https://www.ncbi.nlm.nih.gov/books/NBK326503/. [Accessed on August 10, 2020].

[21] Pandey V, Salam SA, Moda A, Agarwal P, Nath S, Pulikkotil SJ. Effect of the use of snuff on the levels of interleukin$1 \beta$ and interleukin-8 in the gingival crevicular fluid of periodontitis patients. Dent Res J 2015; 12(5):461-8. https://doi.org/10.4103/1735-3327.166222

[22] Montén U, Wennström JL, Ramberg P. Periodontal conditions in male adolescents using smokeless tobacco (moist snuff). J Clin Periodontol 2006; 33(12):863-8. https://doi.org/10.1111/j.1600-051X.2006.01005.x

[23] Hugoson A, Rolandsson M. Periodontal disease in relation to smoking and the use of Swedish snus: Epidemiological studies covering 20 years (1983-2003). J Clin Periodontol 2011; 38(9):809-16.

https://doi.org/10.1111/j.1600-051X.2011.01749.x

[24] Robertson PB, Walsh M, Greene J, Ernster V, Grady D, Hauck W. Periodontal effects associated with the use of smokeless tobacco. J Periodontol 1990; 61(7):438-43. https://doi.org/10.1902/jop.1990.61.7.438

[25] Offenbacher S, Weathers DR. Effects of smokeless tobacco on the periodontal, mucosal and caries status of adolescent males. J Oral Pathol 1985; 14(2):169-81. https://doi.org/:10.1111/j.1600-0714.1985.tb00480.x

[26] Andersson G, Björnberg G, Curvall M. Oral mucosal changes and nicotine disposition in users of Swedish smokeless tobacco products: a comparative study. J Oral Pathol Med 1994; 23(4):161-7.

https://doi.org/10.1111/j.1600-0714.1994.tbo1106.x

[27] Katuri KK, Alluri JK, Chintagunta C, Tadiboina N, Borugadda R, Loya M, et al. Assessment of periodontal health status in smokers and smokeless tobacco users: a cross-sectional study. J Clin Diagn Res 2016; 10(10):ZC143-ZC146. https://doi.org/10.7860/JCDR/2016/22160.8700

[28] Fisher MA, Taylor GW, Tilashalski KR. Smokeless tobacco and severe active periodontal disease, NHANES III. J Dent Res 2005; 84(8):705-10. https://doi.org/10.1177/154405910508400804 
[29] Javed F, Chotai M, Mehmood A, Almas K. Oral mucosal disorders associated with habitual gutka usage: a review. Oral Surg Oral Med Oral Pathol Oral Radiol Endod 2010; 109(6):857-64. https://doi.org/10.1016/j.tripleo.2009.12.038

[30] Warnakulasuriya S, Dietrich T, Bornstein MM, Casals Peidró E, Preshaw PM, Walter C, et al. Oral health risks of tobacco use and effects of cessation. Int Dent J 2010; 60(1):7-30. https://doi.org/10.1922/IDJ_2532Warnakulasuriya24 